\title{
Effect of Temperature and Pressure on Stability of Metallocene Catalyst with Methyl Aluminoxane
}

\author{
Subita Bhagat ${ }^{1}$, Nikhil Prakash ${ }^{2}$ \\ ${ }^{1}$ Assistant Professor, Department of Chemical Engineering, SLIET-Longowal, 148106, \\ India \\ ${ }^{2}$ Assistant Professor, Department of Chemical Engineering, SLIET-Longowal, 148106, \\ India \\ Corresponding Author E-mail: subitabhagat424@gmail.com \\ ${ }^{2}$ nikhilprakash112@yahoo.com
}

\begin{abstract}
Catalysts are used to increase the rate of reactions. Metallocene catalyst is one such effective catalyst generally used to form polymers. The transition of monomers into metal sites at low pressure and temperature were observed in earlier work. Methyl aluminoxane (MAO) used as a catalyst for polymerization and propylene along with varying temperature and pressure. Optimized values of temperature and pressure are worked upon in this work through particle swarm optimization (PSO).Overall process consists of monomer initialization. This phase is termed as forming population for polymerization. Next phase includes population selection. This phase extract monomers based upon the crossover values. Multiple monomers are combined to generate new offspring that is used within next iteration. Metaheuristic approach includes multiple parameters tuning including temperature and pressure with each iteration. By varying the temperature and pressure new polymers are obtained that are stable in nature.
\end{abstract}

Keywords: Particle Swarm Optimization, Metallocene catalyst, Temperature, Pressure.

\section{Introduction}

Metallocene catalyst used to generate polymers that may or may not be stable. Temperature and pressure impact the formation of metal polymers[1]. Through ZeiglerNatta Catalyst, metal polymers were formed but at low temperature. The polymer breaks down as the temperature and pressure increases and hence stability is an issue with this catalyst[2]. For the high-pressure polymerization, MAO catalyst is used for combining monomers for stable polymers. The issue includes the breakage of molecules at high temperature and pressure[3]. To stabilize polymer structure, metallocene catalyst is mixed with polyolefin nanocomposites. The temperature and pressure are varied with the metaheuristic approach and stability of the formed polymers is examined. 
<smiles>C=C</smiles><smiles>CCCCC</smiles>

Figure 1 Polymerization mechanism

Overall process of polymerization can be impacted by the increasing or decreasing the pressure[4]. The pressure will directly impact the mechanical properties of the metallocene catalyst[5]. As the pressure increase the molecular weight of the Propylene-based polymerization[6]. It also causes storage modulus and reduced melting temperature[7]. It is almost critical to analyze the impact of pressure and temperature on the metallocene catalyst[8].

Synthesis of magnesiumsupported Ziegler Natta catalyst with pressure is given within figure 2 .

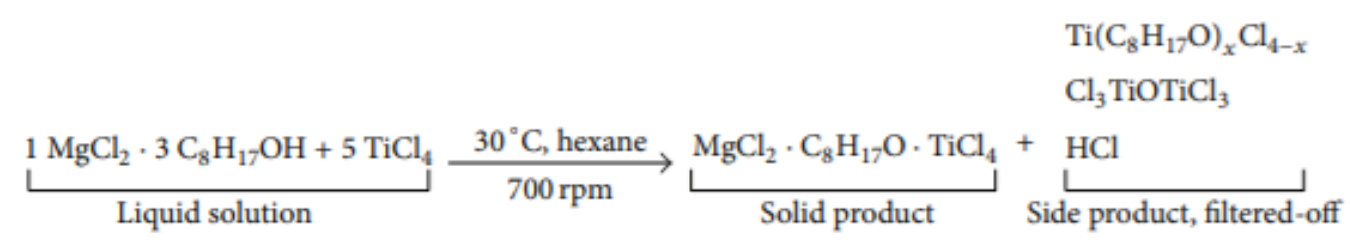

Figure 2 Impact of pressure on Ziegler Natta catalyst

Next section describes methods and material used for achieving the desired objective.

\section{Materials and Methods}

The material for the desired operation includes MAO and Propylene. Other material required includes titanium chloride and magnesium chloride[9]. All of these are used along with MAO with varying temperature and pressure. The simulation-based environment is used for achieving the result. The simulation is conducted within MATLAB[10]. The simulator requires initialization with fixed value of temperature and pressure. At each different iteration this value is varied to observe the impact on polymer structure[11]. The Copolymers (PW) formed during the process of polymerization are stable through the proposed approach. The used data for the polymerization in the proposed work is given within table 1. 
Table 1 Polymerization material with first 10 iteration

\begin{tabular}{|l|l|l|l|l|l|}
\hline Iterations & MAO & Etheline & $\operatorname{Temp}\left({ }^{0} \mathrm{C}\right)$ & Pressure & PW \\
\hline 1 & 71.3 & 5 & 25 & 1 & 162356 \\
\hline 2 & 71.3 & 5 & 25 & 2 & 161233 \\
\hline 3 & 140.23 & 5 & 25 & 3 & 163656 \\
\hline 4 & 140.23 & 5 & 50 & 1 & 165878 \\
\hline 5 & 142.6 & 10 & 50 & 2 & 166587 \\
\hline 6 & 142.6 & 10 & 50 & 3 & 166989 \\
\hline 7 & 143.6 & 10 & 70 & 1 & 165878 \\
\hline 8 & 143.6 & 10 & 70 & 2 & 167548 \\
\hline 9 & 145.6 & 10 & 70 & 3 & 165878 \\
\hline 10 & 145.6 & 10 & 75 & 1 & 166525 \\
\hline
\end{tabular}

\section{Result and Discussion}

The obtained result indicates that as the temperature and pressure increases, the stability of polymers decreases[12]. To enforce stability, pressure can be decreased in the upcoming iterations. The effect of temperature and pressure on PW is analyzed in this section. The result for the same is given in the figure 3 . Number of iteration considered for evaluation are 50 with time 30 minutes. Result corresponding to storage modulus (MP) is described in figure 3.

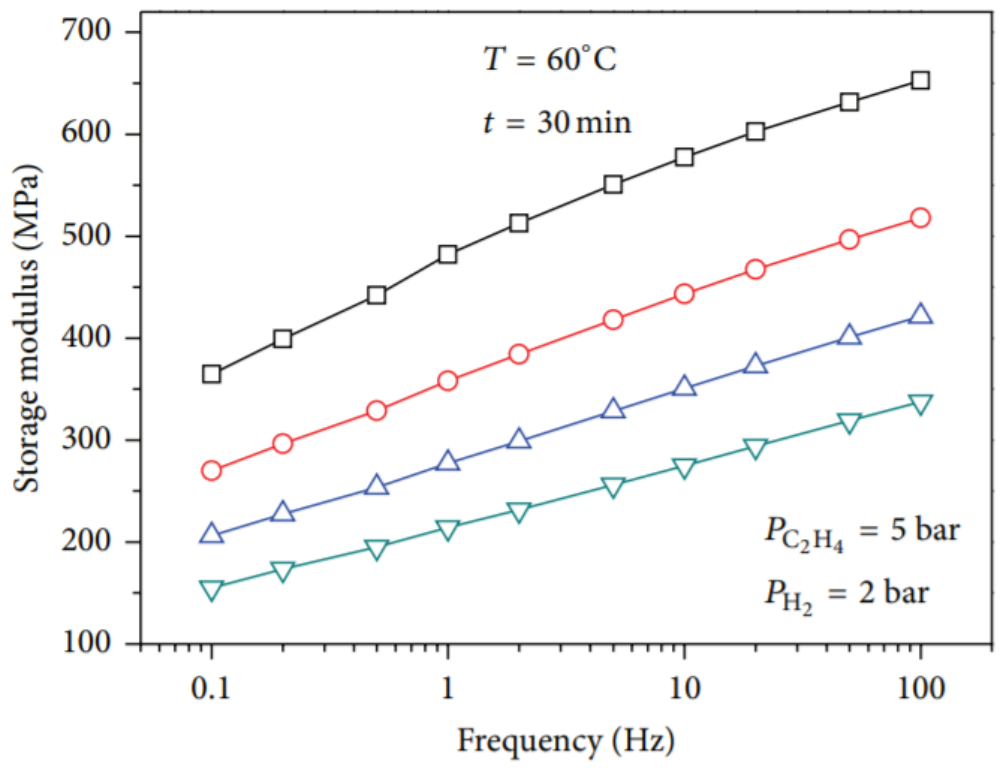

Figure 3 Storage modulus corresponding to polymer formation with different iterations

The increase in polymerization pressure thus causes the termination of polymerization rection. This will happen if temperature is not adjusted. The converse is also true in this case. This means that if temperature is increased and pressure is not adjusted, reaction still terminates[13]. 
Propylene polymerization model is applied to solution phase polymerization of propylene with metallocene catalyst /MAO system and kinetic parameters are obtained[14].Kinetic parameters for $\mathrm{Me} 2 \mathrm{Si}$ [Ind]2ZrCl2 / MAO catalyst system are estimated by simulating the model with experimental data at $25 \mathrm{oC}$ and $75 \mathrm{oC}$ with $\mathrm{Al} / \mathrm{Hf}$ molar ratio of 500[15]. Experimental data for $\mathrm{Al} / \mathrm{Hf}$ ratio of 2000 are used to validate the model at both temperatures.

Table $2 \mathrm{Me} 2 \mathrm{Si}[\mathrm{Ind}] 2 \mathrm{ZrCl} 2$ / MAO catalyst at varying temperature from iteration 1 to 50.ss

\begin{tabular}{|c|c|c|c|}
\hline \multicolumn{2}{|l|}{$\mathbf{T}^{0} \mathrm{C}$} & \multirow{2}{*}{$\begin{array}{r}25 \\
7.870525\end{array}$} & \multirow{2}{*}{$\begin{array}{r}75 \\
15.74105\end{array}$} \\
\hline$k_{\text {in }} \times 10^{3}$ & $\left(M^{-1-1} s^{-4}\right)$ & & \\
\hline$k_{P^{\times 10^{-4}}}$ & $\left(\mathbf{M}^{-1} \cdot s^{-1}\right)$ & 4.172725 & 8.34545 \\
\hline$k_{d^{\prime}} \times 10^{+}$ & $\left(s^{-1}\right)$ & 3.029002 & 6.058004 \\
\hline \multirow{2}{*}{$\begin{array}{l}K_{t M} \\
K_{b} b \times 10^{6}\end{array}$} & $\left(M^{-1} \cdot s^{-1}\right)$ & 4.003503 & 8.007006 \\
\hline & $\left(s^{-1}\right)$ & 2.525051 & 5.050102 \\
\hline $\begin{array}{l}K \times 10^{-2} \\
r b\end{array}$ & $\left(\mathrm{M}^{-1} \cdot s^{-4}\right)$ & 3.631215 & 7.26243 \\
\hline$k_{5} \times 10^{7}$ & $\left(\mathrm{M}^{-1} \cdot \mathrm{s}^{-1}\right)$ & 3.434840 & 6.86968 \\
\hline $\begin{array}{c}k \times 10^{4} \\
s p\end{array}$ & $\left(\mathbf{M}^{-1} \cdot s^{-1}\right)$ & 1.712346 & 3.424692 \\
\hline$K s M$ & $\left(M^{-1} \cdot s^{-1}\right)$ & 7.908342 & 15.816684 \\
\hline$K t, A l$ & $\left(M^{-1} \cdot s^{-1}\right)$ & 5.838210 & 11.67642 \\
\hline$K r A l$ & $\left(\mathrm{M}^{-1} \cdot \mathrm{s}^{-1}\right)$ & 1.155187 & 2.310374 \\
\hline$F(k)$ & $(\rightarrow)$ & 1000 & - \\
\hline
\end{tabular}

The result corresponding to table 2 is given within figure 4 . The analysis indicates that with increased temperature stability is affected but by adjusting pressure stable polymers can be formed.

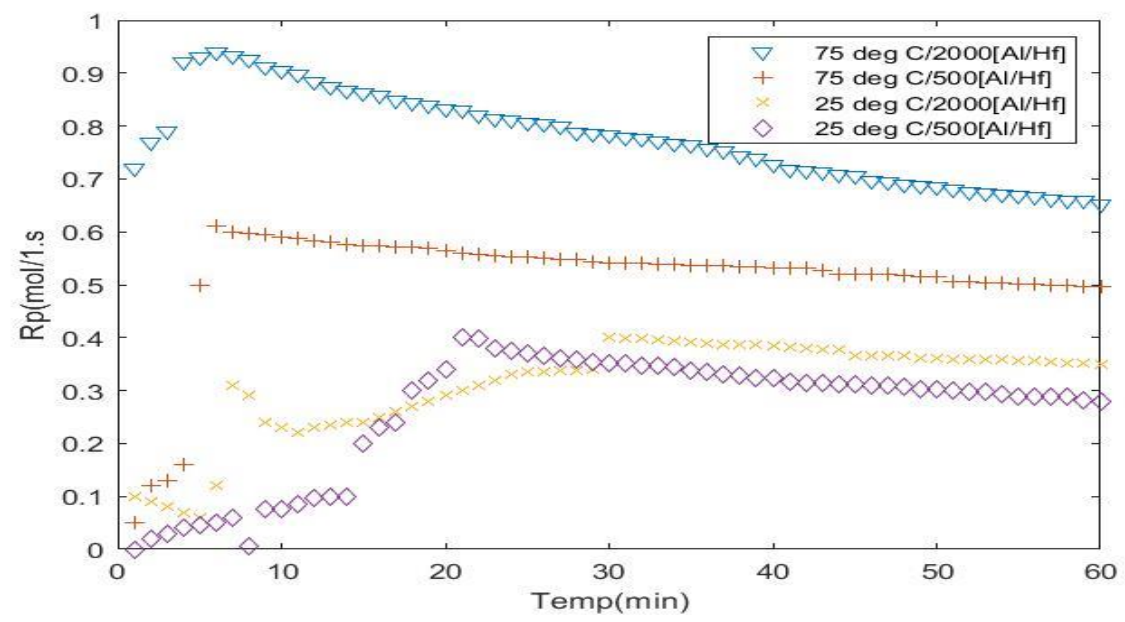

Figure 4 Effect of $\mathrm{Al} / \mathrm{Hf}$ mole ratio on propylene ratecatalyst $=10 \mathrm{uM}, \mathrm{T}=25 \mathrm{C}$ to $\mathrm{T}=75$ $\operatorname{deg} \mathrm{C}, \mathrm{P}=3$ psi 


\section{Conclusion}

The proposed approach uses the particle swarm optimization procedure for determining the optimal pressure and temperature values for obtaining stable polymers. As the temperature increases the stability of the polymers are at stakes. This means they will be unstable and at higher values of temperature, molecules structure breaks down. With propylene and MAO catalyst, keeping pressure constant at 3 Psi gives the stable metal polymers but temperature range must be within 25 to $700 \mathrm{C}$. Also with experiment analysis it was concluded the molecular weight of metallocene catalyst decreases causing easy decoupling of molecules.

\section{References}

[1] P. Kumkaew, L. Wu, P. Praserthdam, and S. E. Wanke, "Rates and product properties of polyPropylene produced by copolymerization of 1-hexene and Propylene in the gas phase with (n-BuCp)2ZrCl2 on supports with different pore sizes," Polymer, vol. 44, no. 17, (2003), pp. 4791-4803. Doi: 10.1016/S0032-3861(03)00473-7.

[2] H. Frauenrath, "Dendronized polymers - Building a new bridge from molecules to nanoscopic objects, ” Progress in Polymer Science (Oxford), vol. 30, no. 3-4, (2005), pp. 325-384. Doi: 10.1016/J.PROGPOLYMSCI.2005.01.011.

[3] M. A. Matsko, L. G. Echevskaya, V. A. Zakharov, M. I. Nikolaeva, T. B. Mikenas, and M. P. Vanina, "Study of multi-site nature of supported Ziegler-Natta catalysts in Propylenehexene-1 copolymerization," Macromolecular Symposia, vol. 282, no. 1, (2009), pp. 157166, Aug. 2009, Doi: 10.1002/MASY.200950816.

[4] G. Grause, M. F. Chien, and C. Inoue, "Changes during the weathering of polyolefins," Polymer Degradation and Stability, vol. 181, (2020), Doi: 10.1016/J.POLYMDEGRADSTAB.2020.109364.

[5] G. Wang, B. Guo, and R. Li, "Synthesis, characterization, and properties of long-chain branched poly(butylene succinate), " Journal of Applied Polymer Science, vol. 124, no. 2, (2012), pp. 1271-1280. Doi: 10.1002/APP.34034.

[6] S. Mehdiabadi, O. Lhost, A. Vantomme, and J. B. P. Soares, "Propylene Polymerization Kinetics and Microstructure of PolyPropylenes Made with Supported Metallocene Catalysts," Industrial and Engineering Chemistry Research, vol. 60, no. 27, (2021), pp. 9739-9754.Doi: 10.1021/ACS.IECR.1C01091/SUPPL_FILE/IE1C01091_SI_001.PDF.

[7] V. Zakharov et al., "Supported ziegler-natta catalysts for Propylene slurry polymerization and control of molecular weight distribution of polyPropylene," Chinese Journal of Polymer Science (English Edition), vol. 26, no. 5, (2008), pp. 553-559, Doi: 10.1142/S0256767908003266.

[8] M. J. Yanjarappa and S. Sivaram, "Recent developments in the synthesis of functional poly(olefin)s, ” Progress in Polymer Science (Oxford), vol. 27, no. 7, (2002), pp. 13471398. Doi: 10.1016/S0079-6700(02)00011-4.

[9] Y. J. Shin, H. X. Zhang, K. B. Yoon, and D. H. Lee, "Preparation of ultra high molecular weight polyPropylene with $\mathrm{MgCl} 2 / \mathrm{TiCl} 4$ catalysts: Effect of temperature and pressure," Macromolecular Research, vol. 18, no. 10, (2010), pp. 951-955. Doi: 10.1007/S13233010-1003-1. 
[10] A. A. Antonov and K. P. Bryliakov, "Post-metallocene catalysts for the synthesis of ultrahigh molecular weight polyPropylene: Recent advances," European Polymer Journal, vol. 142, (2021), p. 110162. doi: 10.1016/J.EURPOLYMJ.2020.110162.

[11] M. Rahaman, M. A. Parvez, J. B. P. Soares, and I. A. Hussein, "Effect of polymerization conditions on thermal and mechanical properties of Propylene/1-butene copolymer made with Ziegler-Natta catalysts," International Journal of Polymer Science, (2014), Doi: 10.1155/2014/654260.

[12] M. A. Parvez, M. Rahaman, M. A. Suleiman, J. B. P. Soares, and I. A. Hussein, "Correlation of polymerization conditions with thermal and mechanical properties of polyPropylenes made with ziegler-natta catalysts," International Journal of Polymer Science, (2014). Doi: 10.1155/2014/549031.

[13] T. Hameed and I. A. Hussein, "Rheological study of the influence of $M W$ and comonomer type on the miscibility of m-LLDPE and LDPE blends," Polymer, vol. 43, no. 25, (2002), pp. 6911-6929. Doi: 10.1016/S0032-3861(02)00627-4.

[14] Resconi, L., Cavallo, L., Fait, A., \& Piemontesi, F, "Selectivity in propene polymerization with metallocene catalysts”, Chemical Reviews, Vol. 100, No. 4, (2000), pp. 1253-1346.

[15] J. C. W. Chien and T. Nozaki, "Propylene-hexene copolymerization by heterogeneous and homogeneous Ziegler-Natta catalysts and the 'comonomer' effect," Journal of Polymer Science Part A: Polymer Chemistry, vol. 31, no. 1, (1993), pp. 227-237. Doi: 10.1002/POLA.1993.080310127. 